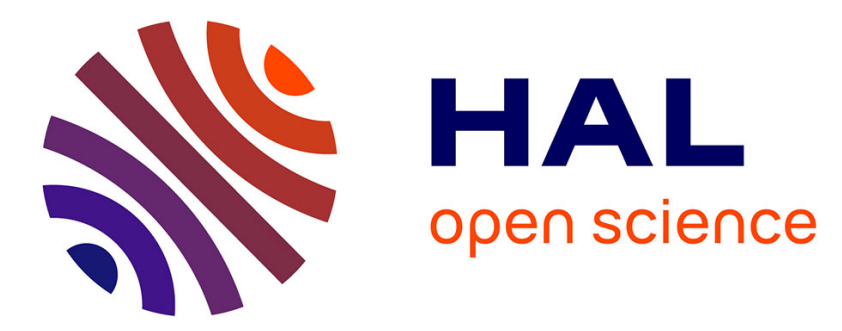

\title{
Screening for hypertension at the hairdresser: a feasibility study in France and Morocco
}

\author{
Jean-Marc Boivin, J. Risse, E. Laurière, M. Burnier
}

\section{To cite this version:}

Jean-Marc Boivin, J. Risse, E. Laurière, M. Burnier. Screening for hypertension at the hairdresser: a feasibility study in France and Morocco. Blood Pressure, 2020, 29 (4), pp.202-208. 10.1080/08037051.2020.1728189. hal-03025851

\section{HAL Id: hal-03025851 \\ https://hal.univ-lorraine.fr/hal-03025851}

Submitted on 26 Nov 2020

HAL is a multi-disciplinary open access archive for the deposit and dissemination of scientific research documents, whether they are published or not. The documents may come from teaching and research institutions in France or abroad, or from public or private research centers.
L'archive ouverte pluridisciplinaire HAL, est destinée au dépôt et à la diffusion de documents scientifiques de niveau recherche, publiés ou non, émanant des établissements d'enseignement et de recherche français ou étrangers, des laboratoires publics ou privés. 


\title{
Screening for hypertension at the hairdresser:
}

\section{A feasibility study in France and Morocco}

\author{
Boivin J.M. ${ }^{1,2}$, Risse $\mathrm{J}^{1}$., Laurière $\mathrm{E}^{1}$., and Burnier $\mathrm{M}^{3}$.
}

\section{Institutions:}

1. Department of General Medicine, Faculty of Medicine of Nancy, University of Lorraine,

2. CIC-P Pierre Drouin, Inserm-CHU of Nancy

3. Service of Nephrology and Hypertension, University Hospital, Lausanne, Switzerland

Key words: Hypertension, screening, prevalence, control rate, North Africa, lowincome

Short title: Screening at the hairdresser

Address for correspondence:

Prof. Jean Marc Boivin

Département de Médecine Générale

Faculté de Médecine de Nancy

Université de Lorraine

CIC-P Inserm-CHU de Nancy

Nancy- France

Email:im.boivin@chru-nancy.fr 


\section{Abstract}

Purpose: Worldwide, hypertension awareness remains globally insufficient. This is particularly true in some population subgroups with a low socio-economic status or in younger adults who have few contacts with healthcare systems. Blood pressure (BP) screening could be done in unusual places such as barbershops as suggested by American authors. However, whether this approach is feasible in Europe or NorthAfrica has never been evaluated. Therefore, we planned a study assessing BP screening in hairdressers in France and Morocco.

Material and Methods: This was a prospective multicenter feasibility study. Twentythree hairdressers in France and 6 in Morocco participated in the study. After information, all consenting customers aged over 18 years were included. Three BP were measured by the customers themselves using a validated Omron M7 Automatic BP device.

Results: In France, 1025 subjects were enrolled and in Morocco, 300 have participated. 370 (36\%) French participants had an elevated BP. Among subjects reporting to be normotensive or not knowing their hypertension status, $31.7 \%$ had a $\mathrm{BP} \geq 135 / 85 \mathrm{mmHg}$. Only $42 \%$ of subjects with an elevated BP contacted their physicians within 3 months but hypertension was confirmed in $3 / 4$ of them. In Morocco, participants were older with only $11.7 \%$ of subjects aged $<50$ y. They had more frequently unknown elevated BP values (71.9\%). BP control in known hypertensive was $42.7 \%$ in France and $17.1 \%$ in Morocco. The procedure was very well accepted and considered as useful in both countries.

Conclusion: BP screening in hairdressers is feasible and well accepted but with a relatively low efficacy. 


\section{Introduction}

Among non-communicable diseases, hypertension is undoubtedly the strongest modifiable risk factor for cardiovascular diseases in developed as well as in developing countries. Thus, it is estimated that high blood pressure (HBP) is responsible for 7.5 million deaths per year worldwide [1]. Today, the prevalence of hypertension is increasing mainly due to the ageing of the populations. One of the major issue in the prevention and management of hypertension is the fact that many hypertensive patients are not aware that they have a high blood pressure [2] [3] . In the PURE study, a large epidemiological survey, which covered many different countries around the world, $53.5 \%$ of patients were not aware of their hypertensive status and therefore were not treated [4]. In France, recent surveys have shown a decrease in the prevalence of adequately controlled hypertension particularly among women, and in addition, hypertension awareness appears to decrease rather than increase according to recent data of the CONSTANCES population cohort [5]. Thus, considering that increasing awareness on blood pressure should be one of the major action needed to address the hypertension-associated health burden, several initiatives have been launched in recent years. One of them is the May Measurement Month (MMM) initiated by the International Society of Hypertension, a program in which more than 1.2 million subjects had their blood pressure measured worldwide [6].

These population programs will contribute to increase the global awareness of hypertension However, they often include subjects who already know they are hypertensive of are being treated. Thus, one major difficulty is the detection of hypertension among populations with less frequent physician contacts for preventive care, such as young male workers or low socio-economic populations. To screen these difficult- to-reach populations, different strategies have been tested including screening programs in pharmacies, shopping centers, or occupational medicine $[7,8]$. However, once again, these approaches were rather ineffective in detecting hypertension in young men. In the United States, a program was setup to detect male subjects of African-American origin with hypertension in barbershops [9- 
12]. The initial results of this initiative demonstrated an increase in physician referrals of undiagnosed subjects and lower blood pressures among those with uncontrolled hypertension HTN [9]. However, whether hairdressers represent an efficient strategy for using limited resources to identify uncontrolled hypertension is still questioned. Moreover, whether this barbershop approach is feasible and provides similar benefits in other countries with different customs and community behaviors has never been investigated so far.

Therefore, we designed a prospective feasibility study to assess whether hypertension screening can be performed in hairdressers in France and Morocco. The primary objective of the study was to assess the feasibility and the effectiveness of a hypertension screening strategy with self-blood pressure measurements in hairdressers. In addition, we compared the efficiency of our strategy in two populations whose health care structures, local habits and medical access are very different i.e Morocco and France. At last, we evaluated the acceptability of the strategy by participants.

\section{Subjects and methods}

This prospective multicenter study of high blood pressure screening was conducted in France and Morocco between January and April 2013. Twenty-three hairdressers in France and six in Morocco accepted to participate in the study without financial compensation. A protocol information flyer was delivered to all customers and all consenting customers aged over 18 years were included. Only adult male and female patients' results were analyzed. Three validated humeral Omron M7 Automatic BP monitors ${ }^{\circledR}$ connected to a printer were available in each hairdresser. Information on how to use the devices were provided on flyers and customers could get the support of the hairdresser who were carefully informed and taught on the procedure. The subjects took themselves three consecutive BP (one measure per min) after being comfortably seated for at least 5 minutes. Values were automatically averaged and printed. Hypertension was defined as an average of three SBPM $\geq 135$ and/or 
$>85 \mathrm{mmHg}$, according to the 2013 European Society of Hypertension guidelines regarding self-measured BP [13].

Additional data were collected regarding gender, age, hypertensive medications and the knowledge of being hypertensive or not. French customers were free to give their phone number to be contacted 3 months later for a short interview regarding the actual follow-up in case of elevated BP measured at screening.

All analyses were carried out using the SAS R9.2 software (SAS Institute, Cary, NC, USA). Continuous variables were presented as frequency and categorical variables were described as frequency and percent. The between-groups comparisons were performed using the Mann-Whitney test for continuous variables, and the Chi-Square test (or Fisher's test when requested) for categorical variables. The significance level was set to $p<0.05$.

\section{Results:}

In France, 1025 subjects were enrolled and in Morocco, 300 accepted to participate. Among them, data were complete and evaluable in 1011 French [752 women (74.3\%) and 259 men (25.7\%)] and 299 Moroccan [157 women (52.5\%) and 142 men (47.5\%)] subjects respectively. Table 1 shows some characteristics of the two populations. Participants from Morocco were significantly older and had a higher mean systolic and diastolic BP.

Table 2 presents the distribution of participants according to age and the presence or absence of known hypertension before the screening in the two populations. Regarding the age distribution, it was well balance trough age categories in the French group and $46.3 \%$ of the participants were younger than age 50y. In contrast, very few participants from Morocco were $<50$ y $(11.7 \%)$. Elderly patients were few in both countries. In France, as expected, the prevalence of known hypertension increased with age $(p<0.001$ for trend). In Morocco, this trend was not observed probably because of the small number of subjects and because most subjects (84.5\%) either did not know about hypertension or were supposedly normotensive. 
As shown in Table 3, when measured at the hairdresser, 370 (36\%) French participants had an elevated BP and the other $64 \%$ had a normal BP. Among French subjects who reported to be normotensive or not knowing if they suffered from hypertension, $31.7 \%$ had an elevated BP suggesting that they might be hypertensive. About 19\% of French participants declare that they knew they were hypertensive and among those only $42.7 \%$ had a controlled BP. The profile differed substantially among the Moroccan participants. Indeed, $71.9 \%$ of them had an elevated BP and only $13.7 \%$ of participants knew they were hypertensive. In supposedly normotensive subjects, $70 \%$ had an elevated BP compatible with a hypertensive status. Among hypertensive subjects, only $17 \%$ had a controlled BP.

Two hundred and eighty one French participants have accepted to be contacted with a phone call, 3 months after their participation. Among the 102 contacted participants with a BP $\geq 135 / 85 \mathrm{mmHg}, 42 \%(n=43)$ consulted their doctor during the three following months to check their BP and an elevated office BP $(>140 / 90 \mathrm{mmHg}$ ) was confirmed in 30 of them. Concerning the perception of this screening program by participants, $86,1 \%(n=242)$ felt that this experience was interesting, $75,8 \%(n=213)$ innovative, only $1,8 \%(n=5)$ useless, and none felt that this strategy was inappropriate.

\section{Discussion:}

All national and international surveys on hypertension prevalence, awareness and treatment show repeatedly and consistently that hypertension prevalence increases, mainly due to aging and metabolic disorders, awareness remains low and the percentage of hypertensive patients well controlled is below $50 \%$ in most countries. Some subgroups of patients with hypertension are particularly difficult to reach. This is the case of young working males but also subjects with a low income and social status, who underuse the health care systems. Some of these populations are at high cardiovascular risk. In 2011, Victor RN et al demonstrated for the first time that BP measurement in barbershops was an effective way of 
accessing subgroups of the population such as Black males who have a high prevalence of hypertension and a high cardiovascular risk but less physician interactions and a low participation to screening programs [9]. This approach was found to be effective in improving BP control [9]. However, the cost-effectiveness of this approach remained questionable. Moreover, whether such an approach could be applied outside the US remained unknown. To our knowledge, our study is the first to demonstrate that hypertension screening in hairdressers is also feasible in Europe and North-Africa with an excellent acceptation by customers, more than 1000 subjects having accepted to participate in France within four months and 300 in Morocco but with a relatively low final yield. In contrast to the US program, BP measurements were not limited to males but were open to any adult older than 18 years going to the hairdresser. Thus, as observed in pharmacy screening programs, more females than males participated in France. However, this was not the case in Morocco with an equal percentage of males and females, but very few subjects younger than 50 years.

Our study enabled to identify $32 \%$ of possibly undiagnosed or untreated hypertensive patients in France (43\% for men and $27 \%$ for women), a percentage which is close to that obtained in the ESTEBAN survey in 2015 [5]. In Morocco, this figure was much higher at $70 \%$ suggesting that the majority of Moroccans do not know their BP, and whether they are hypertensive or not. In the same classes of age, Tazi et al, reported comparable figures [14]. Interestingly, when an elevated BP was measured at the hairdresser, less than half of the subjects $(42 \%)$ recontacted three months later, actually went to their physician to confirm or infirm the diagnosis of hypertension. This disappointing impact on the number of consultations in case of elevated BP in France may be because subjects were young, and prior office BP measurements were considered as "normal". Yet, among the 43 subjects who consulted their physician after the screening, the diagnosis was confirmed in 30 of them, suggesting that hairdresser screening may be a useful approach to detect some new hypertensive subjects in the population and that BP measurements were adequate in the screening process. Yet, against our expectations, few young male subjects participated in 
the study particularly in Morocco suggesting that the approach may need to be adapted further to reach the adequate population groups. Thus, our results question how the efficacy of such a detection process might be improved. In order to be most effective, the hairdresser screening should probably be coupled to the distribution of more comprehensive information on the health impact of an elevated BP using flyers or tablets that subjects can watch during the haircut. In addition, stronger recommendations should be given to verify the level of BP in another occasion by a healthcare professional be it a physician, a nurse or a pharmacist. In a recent study, Victor et al have demonstrated that barbershop screening coupled with medication management in barbershops by specialty-trained pharmacists is the most effective approach for already treated subjects [11]. Another approach might be to associate the BP screening with another healthcare service. In Sweden, BP screening was proposed in dental offices or by hygienists as part of a global management of dental health [15]. A similar approach has recently been implemented in the US with some success [16].

Our data also provided some information on BP control among treated hypertensive patients based on self-measured BP. In France, $42.7 \%$ of subjects known to be hypertensive had a well-controlled BP, i.e slightly less than what was observed in the FLAHS survey in 2017 (50.9\%) [17]. In Morocco, only $17 \%$ of subjects known to be hypertensive had a controlled BP. This number is much lower than the $46.8 \%$ published recently by Alami et al [18] but in this latter survey, only recently treated patients ( 3 months) were enrolled. One goal of the study was to test whether this approach was not only feasible but also accepted by the customers. In France, the acceptation was high and only $5 \%$ of the participants considered these measurements as useless. This could encourage further adaptations of the screening process in the future. The large difference observed between France and Morocco suggest that the procedure should probably be adapted to the local conditions and customs.

This study has limitations: the first is the low enrollment in Morocco, with a greater prevalence of patients with elevated BP. This was because selected locations were in low socioeconomic level areas with limited access to doctors and older population. However, this 
may also represent the ideal setting to screen for and detect new cases of hypertension. The second limit is the study design. Indeed, this was essentially a feasibility study and not an interventional study aiming at improving BP control. At last, considering the setting, few clinical parameters beyond BP were collected. There was no selection criteria for the enrolment of subjects in the screening program. However, this does not prevent from bias and whether the distribution of our participants reflects that of the population cannot be ascertain. Thus, one cannot generalize our data to other populations.

\section{Conclusion}

About 15 millions of French people are hypertensive and 4 million of them are undiagnosed [5]. More than 7 million Moroccans are hypertensive [14] and one does not know how many of them are undiagnosed. Measuring BP during a haircut may help to identify unknown or uncontrolled hypertensive patients in proportions consistent with published data in USA (threshold $\geq 135 / 85 \mathrm{mmHg}$ ).

Mass screening campaigns as performed during the last 3 or 4 decades in supermarkets or pharmacies have generally failed to reach low-income populations that have rare contacts with the health care systems but are often at high cardiovascular risk [7]. In order to have access to a broader number of possibly hypertensive subjects, one should surprise the public and offer them to measure their BP in unusual places, making them participating in their own care. The results of our feasibility study may further inspire high BP screening in unconventional spots in particular in developing countries where direct access to health care may be limited. 


\section{References:}

1. Organisation WH. Global Health Observatory (GHO) data 2018 [Available from: http://www.who.int/gho/ncd/risk factors/blood pressure prevalence text/en/.

2. Olsen MH, Angell SY, Asma S, Boutouyrie P, Burger D, Chirinos JA, et al. A call to action and a lifecourse strategy to address the global burden of raised blood pressure on current and future generations: the Lancet Commission on hypertension. Lancet. 2016;388(10060):2665-712.

3. Charfan M, J, Asmar R, Chahine MN, Zeidan RK, Farah R, et al. Prevalence and risk factors of hypertension: A nationwide cross-sectional study in Lebanon. J Clin Hypertens (Greenwich). 2018;20(5):867-79.

4. Chow CK, Teo KK, Rangarajan S, Islam S, Gupta R, Avezum A, et al. Prevalence, awareness, treatment, and control of hypertension in rural and urban communities in high-, middle-, and low-income countries. JAMA. 2013;310(9):959-68.

5. Perrine AL LC, Blacher J, Olié V. L’hypertension artérielle en France : prévalence, traitement et contrôle en 2015 et évolutions depuis 2006. Bull Epidémiol Hebd 2018; 10: 170179.

6. Beaney T, Schutte A.E., Tomaszewski M., Ariti C, Burrell L. M., Castillo R.R., et al, on behalf of the MMM Investigators. May Measurement Month 2017: an analysis of blood pressure screening results worldwide. Lancet Glob Health. 2018;6(7):e736-e743.

7. Ferdinand KC. The Healthy Heart Community Prevention Project: a model for primary cardiovascular risk reduction in the African-American population. J Natl Med Assoc. 1995;87(8 Suppl):638-41.

8. Schnohr P, Hansen AT. A blood pressure information campaign including mass screening for hypertension in Copenhagen Supermarkets. Acta Med Scand. 1976;199(4):269-72.

9. Victor RG, Ravenell JE, Freeman A, Leonard D, Bhat DG, Shafiq M, et al. Effectiveness of a barber-based intervention for improving hypertension control in black men: the BARBER-1 study: a cluster randomized trial. Arch Intern Med. 2011;171(4):342-50. 10. Victor RG, Lynch K, Li N, Blyler C, Muhammad E, Handler J, et al. A ClusterRandomized Trial of Blood-Pressure Reduction in Black Barbershops. N Engl J Med. 2018;378(14):1291-301.

11. Victor RG, Blyler C, Elashoff RM. A Trial of Blood-Pressure Reduction in Black Barbershops. N Engl J Med. 2018;379(2):200-1.

12. Hess PL, Reingold JS, Jones J, Fellman MA, Knowles P, Ravenell JE, et al. Barbershops as hypertension detection, referral, and follow-up centers for black men. Hypertension. 2007;49(5):1040-6. 
13. Mancia G, Fagard R, Narkiewicz K, Redón J, Zanchetti A, Böhm M, et al. 2013 $\mathrm{ESH} / \mathrm{ESC}$ Guidelines for the management of arterial hypertension: the Task Force for the management of arterial hypertension of the European Society of Hypertension (ESH) and of the European Society of Cardiology (ESC). J Hypertens. 2013;31(7):1281-357.

14. Tazi MA, Abir-Khalil S, Chaouki N, Cherqaoui S, Lahmouz F, Srairi JE, et al.

Prevalence of the main cardiovascular risk factors in Morocco: results of a National Survey, 2000. J Hypertens. 2003;21(5):897-903.

15. Engström S, Berne C, Gahnberg L, Svärdsudd K. Efficacy of screening for high blood pressure in dental health care. BMC Public Health. 2011;11:194.

16. Blair T, Lawson S, Porter H. Blood Pressure Screening in the Dental Office. Ann Fam Med. 2017; 15(3): 278.

17. Girerd X. FLAHS Survey 20172017 [Available from: http://www.comitehta.org/wpcontent/uploads/2018/01/FLAHS2017 Diapo.pdf.

18. Alami M, El Hattaoui M, Seqat M, Sadik J, Aouad A Benghanem Gharbi M. Control of blood pressure and cardiovascular risk in Moroccan patients with newly diagnosed hypertension: a 3-month observational study in primary care. Ther Adv Cardiovasc Dis. 2017 $11(2): 49-56$. 
Table 1: Characteristics of participating subjects in the two populations

\begin{tabular}{|c|c|c|c|c|c|c|c|c|}
\hline & \multicolumn{4}{|c|}{ France } & \multicolumn{4}{|c|}{ Morocco } \\
\hline & $\mathbf{n}$ & mean \pm SD & median (IIQ) & extreme & $\mathbf{n}$ & mean $\pm S D$ & median (IIQ) & extreme \\
\hline Age (years) & 1011 & $50 \pm 18$ & $51(37-63)$ & $18-97$ & 299 & $61 \pm 11$ & 61 (54-69) & $25-86$ \\
\hline SBP (mmHg) & 1020 & $128 \pm 17$ & $126(115-138)$ & 83-196 & 299 & $141 \pm 15$ & $140(132-149)$ & $107-190$ \\
\hline $\mathrm{DBP}(\mathrm{mmHg})$ & 1020 & $76 \pm 10$ & $76(69-83)$ & $45-112$ & 299 & $82 \pm 12$ & 80 (73-93) & $53-110$ \\
\hline
\end{tabular}

Table 2 : Distribution of the subjects in the two populations according to age and the knowledge about hypertension

\begin{tabular}{|c|c|c|c|c|c|c|}
\hline \multirow[b]{2}{*}{ Age (yo) } & \multicolumn{2}{|c|}{ n (\%) } & \multicolumn{2}{|c|}{ No HT or unknown HT } & \multicolumn{2}{|c|}{ Known HT } \\
\hline & France & Morocco & France & Morocco & France & Morocco \\
\hline$<35$ & $228(22.6)$ & $6(2)$ & $226(99.1 \%)$ & $6(100 \%)$ & $2(0.9 \%)$ & 0 \\
\hline $35-49$ & 240 (23.7) & 29 (9.7) & $226(94.2 \%)$ & $26(89.7 \%)$ & $14(5.8 \%)$ & $3(10.3 \%)$ \\
\hline $50-64$ & $307(30.4)$ & $150(50.2)$ & $242(78.8 \%)$ & $128(85.3 \%)$ & $65(21.2 \%)$ & $22(14.7 \%)$ \\
\hline $65-79$ & $184(18.2)$ & $103(34.5)$ & 954 (51.4\%) & 87 (84.5\%) & $89(48.6 \%)$ & $16(15.5 \%)$ \\
\hline$\geq 80$ & $52(5.1)$ & $11(3.7)$ & 31 (59.6\%) & 11 (100\%) & 21 (40.4\%) & 0 \\
\hline TOTAL & $1011(100 \%)$ & $299(100 \%)$ & $820(81.1 \%)$ & $258(86.3 \%)$ & $191(18.9 \%)$ & $41(13.7 \%)$ \\
\hline
\end{tabular}


Table 3: Blood pressure measurements in the barbershop: proportion of subjects with an elevated or normal SMBP according the knowledge of their hypertensive status. The pink areas indicate the possibly unrecognized hypertensive subjects and the green areas the percentage of hypertensive patients well controlled.

\begin{tabular}{|c|c|c|c|c|c|c|}
\hline FRANCE & \multicolumn{3}{|c|}{$S M B P \geq 135$ and/or $85 \mathrm{mmHg}$} & \multicolumn{3}{|c|}{ SMBP $<135$ and/or $85 \mathrm{mmHg}$} \\
\hline Total: $1011(100 \%)$ & \multicolumn{3}{|c|}{$370(36 \%)$} & \multicolumn{3}{|c|}{$641(64 \%)$} \\
\hline \multirow{2}{*}{$\begin{array}{c}\text { Known normotensive } \\
\text { or HT not known: } 819 \\
(81.1 \%)\end{array}$} & \multirow{2}{*}{$260(31.7)$} & Female & $163(62.7)$ & \multirow{2}{*}{$559(68.3)$} & Female & $431(77.1)$ \\
\hline & & Male & 97 (37.3) & & Male & $128(22.9)$ \\
\hline \multirow{2}{*}{ Known HT: 192 (18.9\%) } & \multirow{2}{*}{$110(57.3)$} & Female & $90(81.8)$ & \multirow{2}{*}{$82(42.7)$} & Female & $68(82.9)$ \\
\hline & & Male & 20 (18.2) & & Male & 14 (17.1) \\
\hline
\end{tabular}

\begin{tabular}{|c|c|c|c|c|c|c|}
\hline MOROCCO & \multicolumn{3}{|c|}{ SMBP $\geq 135$ and/or $85 \mathrm{mmHg}$} & \multicolumn{3}{|c|}{$\mathrm{SMBP}<135$ and $/$ or $85 \mathrm{mmHg}$} \\
\hline Total: $299(100 \%)$ & \multicolumn{3}{|l|}{$215(71.9 \%)$} & \multicolumn{3}{|l|}{$84(28.1 \%)$} \\
\hline \multirow{2}{*}{$\begin{array}{c}\text { Known normotensive } \\
\text { or HT not known: } 258 \\
(86.3 \%)\end{array}$} & \multirow{2}{*}{$181(70.2)$} & Female & $98(54.1)$ & \multirow{2}{*}{$77(29.8)$} & Female & $38(49.4)$ \\
\hline & & Male & $83(45.9)$ & & Male & $39(50.6)$ \\
\hline \multirow{2}{*}{ Known HT: 41 (13.7\%) } & \multirow{2}{*}{$34(82.9)$} & Female & $17(50.0)$ & \multirow{2}{*}{$7(17.1)$} & Female & $4(57.2)$ \\
\hline & & Male & $17(50.0)$ & & Male & $3(42.8)$ \\
\hline
\end{tabular}

